\title{
Pour point depression and flow improvement of waxy crude oil using polyethylene glycol esters of cashew nut shell liquid
}

\author{
William Iheanyi Eke ${ }^{1,3}$ (D) Sampson Kofi Kyei ${ }^{2} \cdot$ Ozioma Achugasim $^{3} \cdot$ Joseph Atubokiki Ajienka $^{1,4}$. \\ Onyewuchi Akaranta ${ }^{1,3}$
}

Received: 14 February 2021 / Accepted: 15 March 2021 / Published online: 1 April 2021

(c) The Author(s) 2021

\begin{abstract}
Wax crystallization and deposition is a major flow assurance problem in production and transportation of waxy crude oil. Conventional flow improvers are mainly high molecular weight synthetic polymers, many of which are eco-toxic. Bio-based flow improvers derived from natural products are promising as inexpensive, eco-friendly alternatives to existing products. In this study, natural cashew nut shell liquid (CNSL) extracted from waste shells of Anacardium occidentale was esterified with polyethylene glycol (PEG). CNSL derivative reduced the pour point of waxy crude oil by $12{ }^{\circ} \mathrm{C}$ at $1000 \mathrm{ppm}$. The effects of CNSL derivatives on wax crystal morphology and micro-structure were studied by cross-polarized microscopy. Micrographs were processed and analyzed with ImageJ software. Addition of CNSL derivatives to oil resulted in changes in wax crystal morphology and micro-structure evidenced by a reduction in average crystal Feret diameter and aspect ratio and increase in boundary fractal dimension, indicative of formation of increasing number of smaller, rounder crystals. Effect of the additives on flow properties of the waxy oil was determined using a co-axial cylinder rotational viscometer. Dynamic viscosity of oil at shear rate of $17 \mathrm{~s}^{-1}$ was reduced by 79.7-90.5\%. CNSL-PEG esters show good prospects as low-cost additives for production, storage and pipeline transportation of waxy crude oil.
\end{abstract}

Keywords Cashew nut shell liquid · Polyethylene glycol · Flow improver · Pour point depressant · Waxy crude oil · Wax crystal morphology

\section{Introduction}

Petroleum accounts for a large proportion of global energy consumption and is a major revenue source for many exporting nations [33]. Paraffinic crude oils are desirable due to ease of refining and high yield of automotive fuel, but their production and transportation are often encumbered by flow

William Iheanyi Eke

eke.iheanyi@aceuniport.org; iheanyiwilliameke@gmail.com

1 World Bank-Africa Centre of Excellence for Oilfield Chemicals Research, University of Port Harcourt, Port Harcourt, Nigeria

2 Department of Chemical Engineering, Kumasi Technical University, Kumasi, Ghana

3 Department of Pure \& Industrial Chemistry, University of Port Harcourt, Port Harcourt, Nigeria

4 Department of Petroleum and Gas Engineering, University of Port Harcourt, Port Harcourt, Nigeria assurance problems resulting from wax precipitation [32, 35].

Waxes crystallize from oil when temperature falls below the wax appearance temperature (WAT). Wax crystals grow and agglomerate in oil with decreasing temperature, forming a large three-dimensional network which changes oil flow behavior. Wax formation increases oil viscosity and with it the energy requirement to pump oil [27, 31]. Other unfavorable outcomes of wax crystallization which can cause mechanical failure in production and transportation systems include the deposition of wax on internal surface of tubings and pipelines, resulting in flow constriction as well as high risk of oil gelation if flow is temporarily stopped $[1,14]$.

Pour point depressants (PPDs)/flow improvers are added to waxy crude oils as a mitigative measure to save cost [23, 31]. Majority of existing flow improvers are high molecular weight polymeric compounds [30]. However, high cost of pour point depressant formulations, selectivity of pour point depressants to crude oils and negative environmental impact 
of oil additives have led to increased interest in developing cheaper eco-friendly flow improvers [32, 34, 36].

Natural products, mainly plant extracts and plant seed oils, such as palm oil, palm kernel oil, olive, soybean and canola oils, in their pristine and derivatized state, are gaining attention as green pour point depressants/flow improvers for waxy crude oils $[3,7,10,12,15,34]$. The ability of plant seed oils and their derivatives to inhibit wax formation relies on interactions between the long carbon chains of the glycerides/free fatty acids and waxes, and the wax inhibitive effect of the polar carboxylic acid groups [3].

Synthetic fatty acids as well as linear and aromatic dicarboxylic acids have been extensively derivatized using polyethylene glycol (PEG), leveraging the dispersant properties of PEG esters for pour point depression of waxy gas oil and middle distillate fuel $[5,28]$. Pour point depression and flow improvement have also been recently reported in waxy crude oils treated with cashew nut shell liquid and its derivatives, showing that with simple chemical modification, cashew nut shell liquid can be derivatized into effective crude oil flow improvers [16-18, 24, 25].

Cashew nut shell liquid is a by-product of the cashew nut industry and is composed of four structurally related alkyl/alkenyl phenols: anacardic acid (6-pentadecyl salicylic acid), cardol (5-pentadecyl resorcinol), cardanol (3-pentadecyl phenol), and 2-methylcardol (2-methyl-5-pentadecyl resorcinol). Natural and technical cashew nut shell liquids contain mainly anacardic acid and cardanol, respectively $[20,40]$. Being a non-food source, cashew nut shell liquid has the advantage over plant seed oils as a cheap, renewable resource for oil industry applications.

It was observed that chemical modification of CNSL via the aromatic ring rather than the alkyl chain gave more effective pour point depressants due to the fact that in the former case, the alkyl chains were free and therefore interacted more effectively with waxes in crude oil as exemplified using cardanol-formaldehyde novolac resins [24, 25]. Utilization of natural cashew nut shell liquid in place of technical (distilled) cashew nut shell liquid for PPD preparation affords an additional functional group (carboxylic acid) which provides an avenue for modification of CNSL by esterification using various alcohols. In previous papers, preparation and application of a sulphonated cashew nut shell liquid esteramine as well as glycerol esters of cashew nut shell liquid as flow improvers were reported [16-18].

In this study, the concept is extended to a polymeric glycol (PEG-400). We report the preparation and application of natural cashew nut shell liquid-PEG derivatives as pour point depressants and low-temperature flow improvers for waxy crude oil. From the health, safety and environment perspectives, polyethylene glycol is suitable for this application being a non-toxic compound. Natural cashew nut shell liquid was extracted from Anacardium occidentale shells and esterified with polyethylene glycol (PEG-400). The effect of the additives on wax crystal morphology and lowtemperature flow properties of waxy crude oil was studied by cross-polarized microscopy and viscometric analysis, respectively.

\section{Materials and methods}

\section{Materials}

Polyethylene glycol (PEG-400) (J.D.Baker); waste cashew nut shell; acetone; Niger-Delta waxy crude oil (donated by Shell Petroleum Development Company, Port Harcourt). The physico-chemical properties of the crude oil sample are shown in Table 1.

\section{Extraction of cashew nut shell liquid}

Cashew nut shell liquid was extracted from the macerated shell using acetone according to the method described in literature [18].

\section{Esterification of natural cashew nut shell liquid}

Natural cashew nut shell liquid $(120 \mathrm{ml})$ was mixed with $122.5 \mathrm{ml}$ of PEG-400 (CNSL: PEG -400 mol ratio of 1:1) and heated for $1 \mathrm{~h}$ at $105-120{ }^{\circ} \mathrm{C}$ in the presence of catalytic amount of sulfamic acid (heterogeneous catalyst). The water of esterification was collected in a Dean-Stark trap till reaction completion. The derivative was labeled $\mathrm{CN}_{1} \mathrm{PG}$. An identical process was carried out using 2:1 mixture of CNSL and PEG-400. The derivative was labeled $\mathrm{CN}_{2} \mathrm{PG}$. The spectra of the derivatives, natural CNSL and PEG were

Table 1 Physico-chemical properties of crude oil sample

\begin{tabular}{lll}
\hline Property & Crude oil & Reference method \\
\hline Specific gravity $\left(15^{\circ} \mathrm{C}\right)$ & 0.839 & ASTM D1298-12b \\
API gravity & 37.2 & \\
Kinematic viscosity $\left(40{ }^{\circ} \mathrm{C}\right) \mathrm{cSt}$ & 6.94 & ASTM D 455-12 \\
Kinematic viscosity $\left(100{ }^{\circ} \mathrm{C}\right)$ & 1.43 & \\
$\quad \mathrm{cSt}$ & & \\
WAT $\left({ }^{\circ} \mathrm{C}\right)$ & 26.1 & ASTM D 5772 \\
Pour point $\left({ }^{\circ} \mathrm{C}\right)$ & 12 & ASTM D 5853-17-A \\
Wax content $(\%)$ & 8.9 & UOP 46-64 \\
Water content $(\%)$ & 0.025 & ASTM D 4006-11 \\
Asphaltene content $(\%)$ & 0.05 & ASTM D 6560 \\
Saturates $(\%)$ & 63.7 & Column chromatography \\
Aromatics $(\%)$ & 31.8 & \\
Resins $(\%)$ & 3.0 & \\
\hline
\end{tabular}


recorded using a Fourier-transform Infrared Spectrophotometer (FTIR).

\section{Evaluation of CNSL derivatives}

\section{Pour point}

To dissolve any wax pre-existing in the oil, the crude oil samples were warmed to $60{ }^{\circ} \mathrm{C}$ using a water bath, prior to additization. Using a Hamilton co. micro-syringe, oil samples contained in the pour point test jar were doped with $500 \mathrm{ppm}, 1000 \mathrm{ppm}, 2000 \mathrm{ppm}, 4000 \mathrm{ppm}$ and $5000 \mathrm{ppm}$ of CNSL derivative. The samples were inserted in the cooling jacket of Stanhope-Seta cloud \& pour point refrigerator and observed for flow every $3{ }^{\circ} \mathrm{C}$ drop in oil temperature according to ASTM D5853-17a-Standard Test Method for Pour Point of Crude Oils (Procedure A).

\section{Optical microscopy}

Microscopy studies of crude oil with and without additives were carried out using an Olympus BX51 cross-polarized microscope. The oil sample was warmed in a water bath to $60^{\circ} \mathrm{C}$ and doped with $1000 \mathrm{ppm} \mathrm{CN}{ }_{1} \mathrm{PG}$ and $4000 \mathrm{ppm}$ $\mathrm{CN}_{2} \mathrm{PG}$, respectively. These dosages were adopted based on the results of pour point analysis, due to the optimal pour point depressant effect of the additives at this concentration. An aliquot of the doped oil was transferred to the quartz sample holder and inserted on the heating block of the Linkam THMS 600 thermal stage. The analysis was automated using Linksys32 software via T95-linkpad system controller. Sample was first heated at a rate of $5{ }^{\circ} \mathrm{C} / \mathrm{min}$ to $60{ }^{\circ} \mathrm{C}$, held at this temperature for $1 \mathrm{~min}$, then cooled to $10^{\circ} \mathrm{C}$ at a rate of $1^{\circ} \mathrm{C} /$ min using liquid nitrogen (via LN95 pump) and water. Wax crystallization process was monitored on a live feed and micrographs captured in $30 \mathrm{~s}$ intervals. The micrographs were processed and analyzed, and the descriptive parameters of wax crystal morphology and micro-structure computed using image $\mathrm{J}$ software. The wax crystals were characterized using size (Feret diameter) aspect ratio and boundary fractal dimension. The boundary fractal dimension was determined by box counting method using software default box sizes of $2,3,4,6,8,12,16,32$ and 64 .

\section{Viscometric analysis}

Viscometric analysis of blank and doped crude oil samples was carried out using Ofite 900 co-axial cylinder rotational viscometer. Prior to analysis, the oil was warmed to $60{ }^{\circ} \mathrm{C}$ in a water bath to dissolve any pre-existing wax, then doped with 1000 ppm $\mathrm{CN}_{1} \mathrm{PG}$ and 4000 ppm $\mathrm{CN}_{2} \mathrm{PG}$, respectively, and transferred to viscometer cup. The shear stress and viscosity of the oil samples were measured at shear rate intervals of $5 \mathrm{rpm}$ and $20 \mathrm{rpm}$ ranging from 10 to $100 \mathrm{rpm}$ $\left(17.02 \mathrm{~s}^{-1}-170.23 \mathrm{~s}^{-1}\right)$ and at temperature intervals of $5{ }^{\circ} \mathrm{C}$ as the oil cooled from $50{ }^{\circ} \mathrm{C}$ to $10^{\circ} \mathrm{C}$.

\section{Results and discussion}

\section{Extraction and esterification of natural CNSL}

Extraction of CNSL using low-boiling solvents (especially ketones) gives good yield (approximately 35\%), of natural cashew nut shell liquid which contains $65-90 \%$ anacardic acid [18, 20, 21, 39]. Figure 1 shows the FTIR spectra of $\mathrm{CN}_{1} \mathrm{PG}$ (monoester), $\mathrm{CN}_{2} \mathrm{PG}$ (diester), natural CNSL and PEG-400. The broad bands at $3421.7 \mathrm{~cm}^{-1}$ and $3369.5 \mathrm{~cm}^{-1}$ in the spectrum of $\mathrm{CN}_{1} \mathrm{PG}$ and $\mathrm{CN}_{2} \mathrm{PG}$, respectively, have their origin in the phenolic $\mathrm{O}-\mathrm{H}$ vibration of CNSL $[2,6,19]$. The band at $3011.7 \mathrm{~cm}^{-1}-3008.0 \mathrm{~cm}^{-1}$ is due to $=\mathrm{C}-\mathrm{H}$ stretching in the 15 -carbon chain of $\mathrm{CNSL}$ [19] This band is further confirmed by $=\mathrm{C}-\mathrm{H}$ deformation (bending) vibrations occurring at $708.2 \mathrm{~cm}^{-1}$ [19]. Also, $2922.1 \mathrm{~cm}^{-1}$ and $2855.2 \mathrm{~cm}^{-1}$ correspond to $\mathrm{C}-\mathrm{H}$ vibrations of methylene and methyl groups of the hydrocarbon chain [2, 13]. Methyl $\mathrm{C}-\mathrm{H}$ stretch vibration of the aliphatic chain of CNSL is confirmed by deformation vibration at $1453.7 \mathrm{~cm}^{-1}$ and $1449.9 \mathrm{~cm}^{-1}[2,13]$. The $\mathrm{C}=\mathrm{C}$ stretch of benzene ring of anacardic acid gave rise to the band at $1602.8 \mathrm{~cm}^{-1}[13$, 19]. The sharp band at $1699 \mathrm{~cm}^{-1}$ in the spectrum of natural CNSL is due to the $\mathrm{C}=\mathrm{O}$ of carboxylic acid (attached to aromatic ring), which is confirmed by the $\mathrm{C}-\mathrm{O}$ stretch vibrations of the acid at $1211.4 \mathrm{~cm}^{-1}[6,13,19]$. The intense band at $1095 \mathrm{~cm}^{-1}$ in the spectrum of PEG-400 is indicative of the long $-\mathrm{C}-\mathrm{O}-\mathrm{C}-$ chain, which overlaps with the $\mathrm{C}-\mathrm{O}$ vibration of primary alcohol of PEG [6, 13], [19]. The characteristic $\mathrm{C}=\mathrm{O}$ band of carboxylic group of CNSL is absent in the spectra of $\mathrm{CN}_{1} \mathrm{PG}$ and $\mathrm{CN}_{2} \mathrm{PG}$ and is replaced by new bands appearing at $1714.5-1722.0 \mathrm{~cm}^{-1}$ and at $1244.9 \mathrm{~cm}^{-1}$ which correspond to $\mathrm{C}=\mathrm{O}$ and $\mathrm{C}-\mathrm{O}$ vibrations of ester groups, respectively, indicating the formation of ester links between CNSL and PEG [11, 13, 19]. In addition, the transmittance value of the $\mathrm{O}-\mathrm{H}$ band $\left(1095.8 \mathrm{~cm}^{-} 1\right)$ sequentially increases from PEG-400 to $\mathrm{CN}_{1} \mathrm{PG}$ and $\mathrm{CN}_{2} \mathrm{PG}$, in that order, suggesting diminishing presence of the absorbing species $(\mathrm{O}-\mathrm{H}$ groups of PEG) as they are converted to ester bonds with increasing mole ratio of CNSL. The transmittance value at the $\mathrm{C}-\mathrm{O}$ and $\mathrm{C}=\mathrm{O}$ frequency likewise decreases in $\mathrm{CN}_{2} \mathrm{PG}$ compared to $\mathrm{CN}_{1} \mathrm{PG}$, indicating increasing number of absorbing species (ester groups) at these frequencies. This 
Fig. 1 FTIR spectra of natural CNSL, PEG-400 and CNSLPEG esters

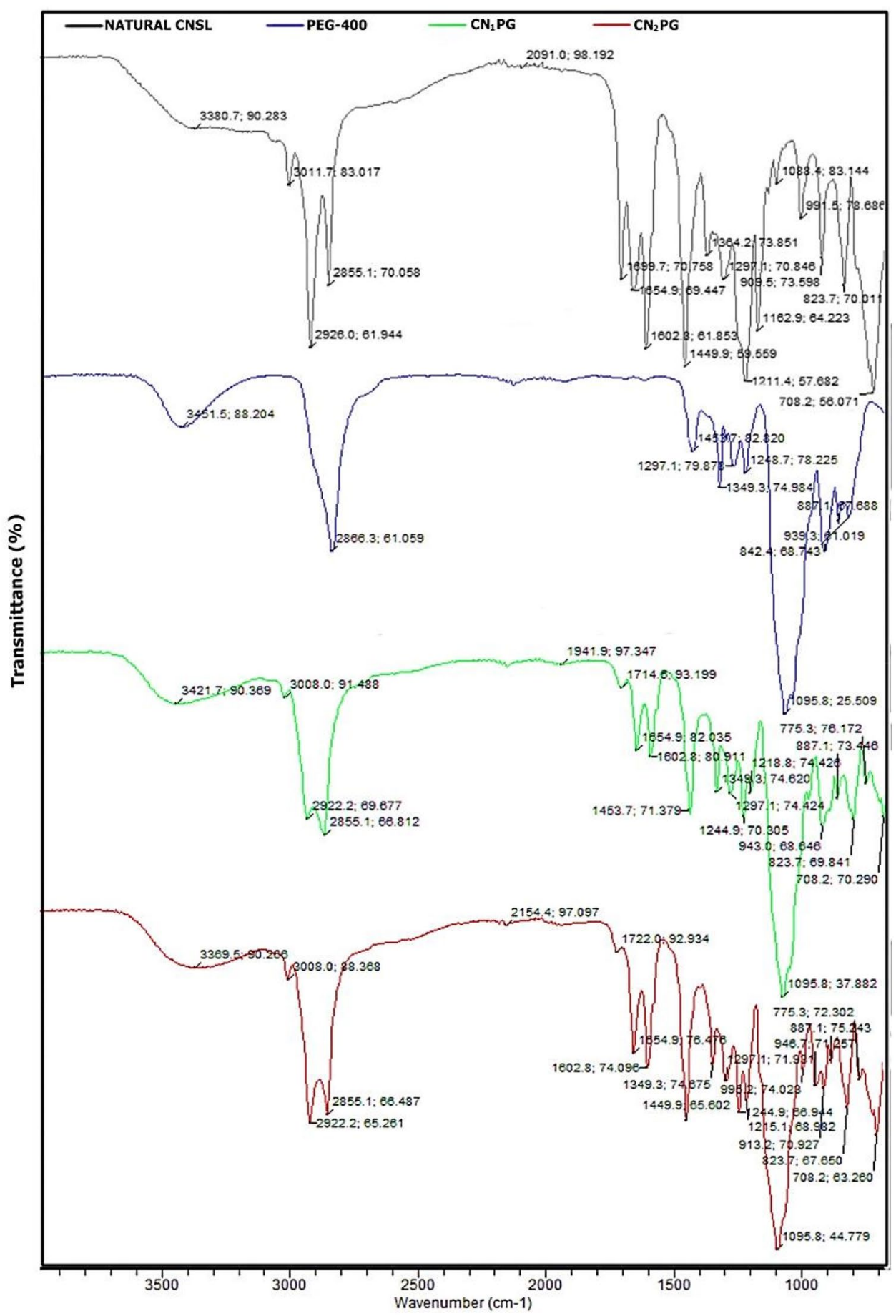

suggests a higher degree of esterification in $\mathrm{CN}_{2} \mathrm{PG}$ (diester) compared to $\mathrm{CN}_{1} \mathrm{PG}$ (monoester) [22].
Effect of CNSL-PEG esters on pour point

The effect of additive dosage on pour point of crude oil
Table 2 Effect of additive dosage on pour point of crude oil

\begin{tabular}{llllllll}
\hline Dosage $(\mathrm{ppm})$ & & 0 & 500 & 1000 & 2000 & 4000 & 5000 \\
\hline Pour point $\left({ }^{\circ} \mathrm{C}\right)$ & $\mathrm{CN}_{1} \mathrm{PG}$ & 12 & 3 & 0 & 6 & 9 & 9 \\
& $\mathrm{CN}_{2} \mathrm{PG}$ & 12 & 9 & 9 & 6 & 0 & 9
\end{tabular}


is presented in Table 2. Oil pour point was reduced by a maximum of $12{ }^{\circ} \mathrm{C}$ using $1000 \mathrm{ppm} \mathrm{CN}_{1} \mathrm{PG}$ and $4000 \mathrm{ppm}$ $\mathrm{CN}_{2} \mathrm{PG}$, respectively. $\mathrm{CN}_{1} \mathrm{PG}$ shows higher pour point depression efficiency. The pour point depressant effect of the additives increased with increasing dosage up to the optimal dosage above which the pour point began to increase. This suggests that above the optimal dosage, the excess additive molecules have a counter-productive effect on the pour point depressant mechanism, resulting in declining performance of additives [37].

The ability of the additive molecules to interact with waxes and depress the oil pour point originates from the structural features of the alkylphenols which constitute natural CNSL (mainly anacardic acid). Due to its structural similarity with paraffins, the 15-carbon aliphatic chain of CNSL facilitates interaction between additive molecules and paraffins, probably via adsorption, while the polar groups have an inhibitive effect on the wax formation process [25, 42].

\section{Effect of CNSL-PEG esters on wax crystal morphology}

Figure 2 shows the optical micrographs of blank crude oil (without additives) and doped crude oil samples. With decreasing oil temperature (from 20 to $10{ }^{\circ} \mathrm{C}$ ), the wax
Fig. 2 Polarized optical micrograph of crude oil at $\left[20^{\circ} \mathrm{C}\right]$ : (a) Blank oil; (b) Oil doped with 1000 ppm $\mathrm{CN}_{1} \mathrm{PG}$; (c) Oil

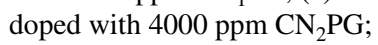
and at $\left[10^{\circ} \mathrm{C}\right]$ : (d) Blank oil; (e) Oil doped with $1000 \mathrm{ppm}$ $\mathrm{CN}_{1} \mathrm{PG}$; (f) Oil doped with 4000 ppm $\mathrm{CN}_{2} \mathrm{PG}$
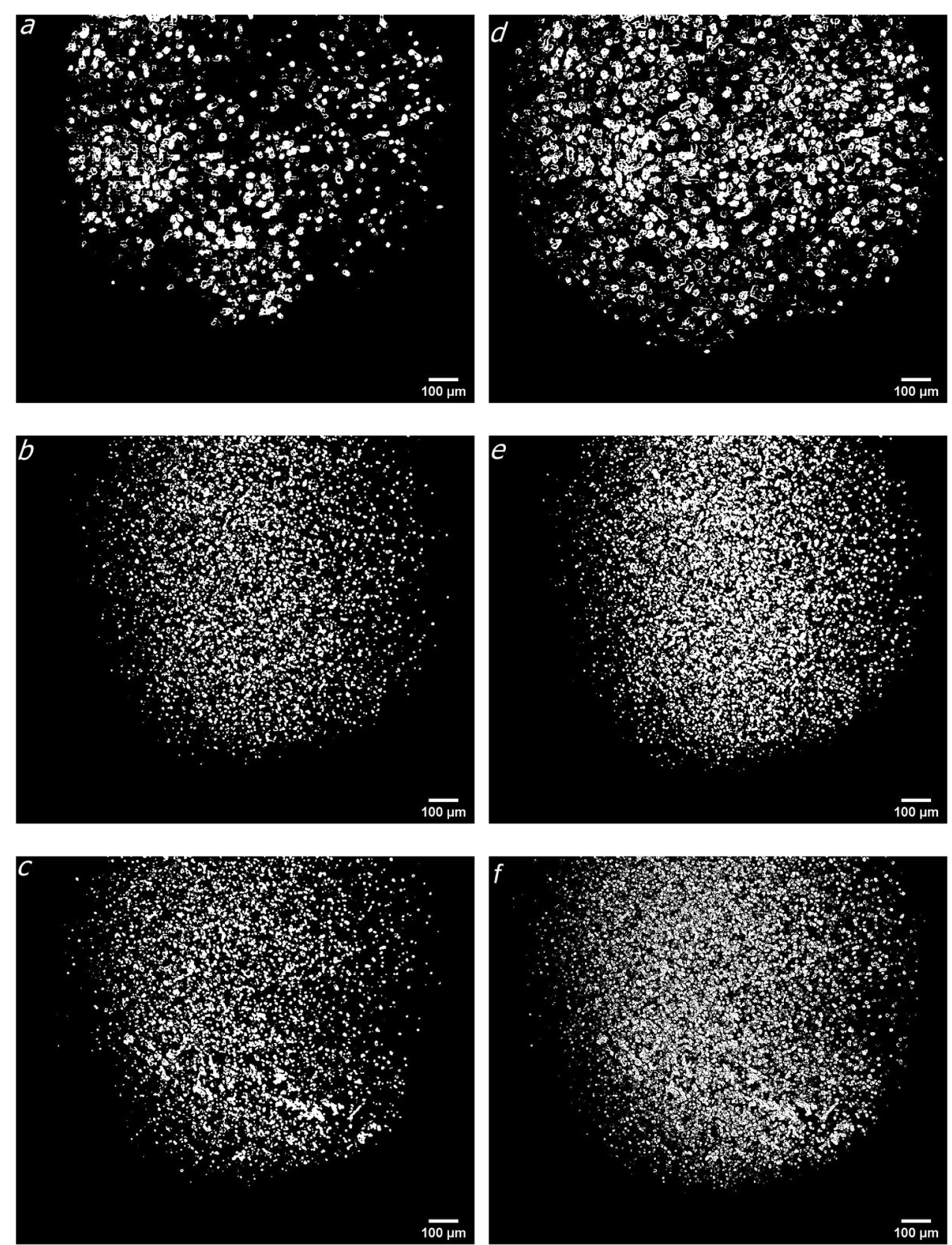
crystal amount in blank oil increases due to crystallization of new wax nuclei and growth of existing wax crystals (Fig. 2a, d) $[26,38]$. Visual comparison of the micrographs before and after addition of $\mathrm{CN}_{1} \mathrm{PG}$ and $\mathrm{CN}_{2} \mathrm{PG}$ shows that wax crystals in doped oil are smaller in size compared to the blank oil at $20^{\circ} \mathrm{C}$ (Fig. 2a, b, c) and $10{ }^{\circ} \mathrm{C}$ (Fig. 2d, e, f).

The wax crystal size distributions (based on the average Feret diameter) of blank and doped crude oil at $20{ }^{\circ} \mathrm{C}$ and $10{ }^{\circ} \mathrm{C}$ are presented in Fig. 3. The average Feret diameter of a wax crystal is the square root of the product of its

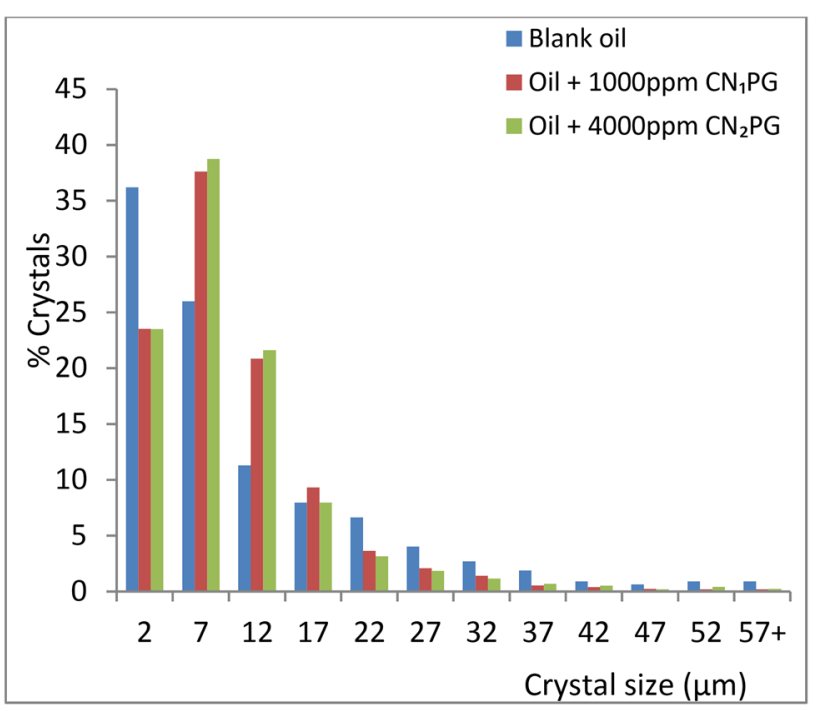

(a)

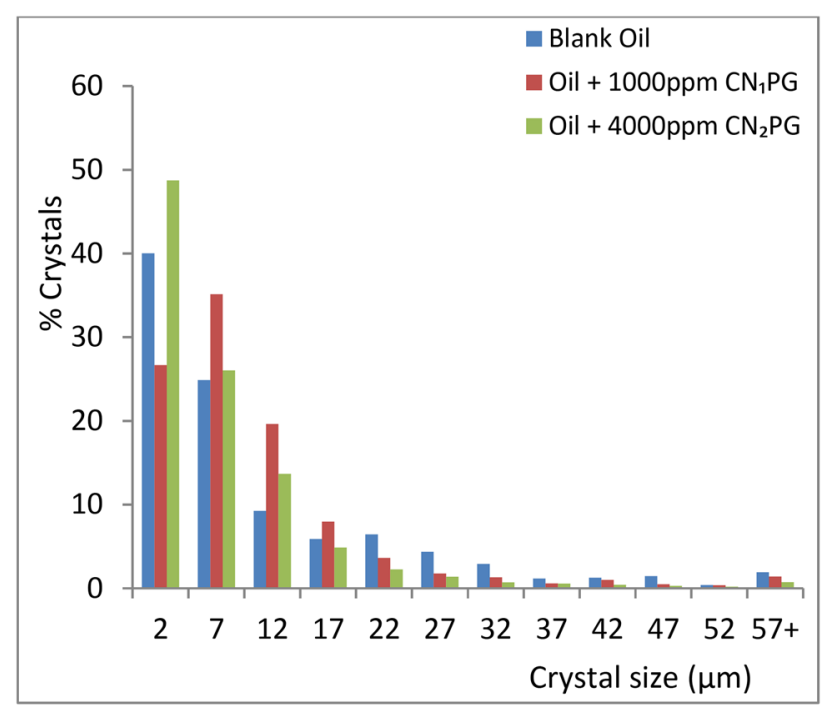

(b)

Fig. 3 Wax crystal size distribution in blank and doped oil at $20{ }^{\circ} \mathrm{C}$ (a); $10{ }^{\circ} \mathrm{C}(\mathbf{b})$ maximum and minimum caliper diameter. It shows that the presence of the additives results in reduction in crystal size. Generally, as temperature decreases, crystal size increases as crystals grow and agglomerate [37]. Large wax structures reduce oil flow ability and favor formation of strong wax networks in oil [41]. In doped oils, the proportion of smaller crystals between 7 and $17 \mu \mathrm{m}$ increases relative to the blank oil, while those $\geq 22 \mu \mathrm{m}$ decrease (Fig. 3).

A quantitative evaluation of the effect of the additives and temperature on the morphology and micro-structure of wax crystals is possible using the microscopic properties of the wax crystals presented in Table 3. Aspect ratio and boundary fractal dimension provide a quantitative description of wax crystal morphology and micro-structure, respectively (Table 3) [8]. The aspect ratio is the ratio of the major axis to minor axis of wax crystal and is the reciprocal of the crystal roundness, whereas the boundary fractal dimension gives an indication of the degree of surface roughness. Increasing aspect ratio indicates elongation of wax crystals and a rodlike crystal shape [8]. Morphology and micro-structure of wax crystals have been cited as the most important factors that influence the low-temperature flow properties of waxy crude oil [44]. Wax crystals in the doped oils are rounder (lower aspect ratio) and show an overall increase in boundary fractal dimension (crystal roughness). Though higher fractal dimension values associated with large wax crystals usually result in stronger wax networks, the apparent increase in boundary fractal dimension in doped oil is likely due to the formation of a large number of much smaller crystals in oil after addition of CNSL derivatives [9] (Fig. 2).

Yi and Zhang [44] also reported that addition of PPD resulted in increase in fractal dimension and reduction in gel point of some waxy crude oils, highlighting that improvement in low-temperature flow properties of waxy crude oil treated with flow improvers, originates from changes in morphology and micro-structure of wax crystals. The microscopy studies suggest that the additives have a dispersive effect on wax crystals in crude oil probably due to the presence of highly polar groups on the additive molecule, such as ester, ether (originating from PEG-400) and

Table 3 Microscopic properties of wax crystals in crude oil

\begin{tabular}{llll}
\hline Temp. & Crude oil & \multicolumn{2}{l}{ Microscopic parameters } \\
\cline { 3 - 4 } & & Aspect ratio & $\begin{array}{l}\text { Boundary frac- } \\
\text { tal dimension }\end{array}$ \\
\hline $20^{\circ} \mathrm{C}$ & Blank oil & 1.70 & 1.48 \\
& Oil $+\mathrm{CN}_{1} \mathrm{PG}$ & 1.61 & 1.58 \\
& Oil $+\mathrm{CN}_{2} \mathrm{PG}$ & 1.61 & 1.57 \\
$10{ }^{\circ} \mathrm{C}$ & Blank oil & 1.73 & 1.60 \\
& Oil $+\mathrm{CN}_{1} \mathrm{PG}$ & 1.65 & 1.70 \\
& Oil $+\mathrm{CN}_{2} \mathrm{PG}$ & 1.67 & 1.72
\end{tabular}


hydroxyl groups. The 15-carbon aliphatic chain of CNSL, as well as the aromatic group, facilitates interactions between additive molecules and oil components [43]. The additive molecules can adsorb onto incipient wax crystals via the alkyl chains while the polar ester, ether and hydroxyl groups induce electrostatic repulsion between small wax crystals onto which the additives molecules are adsorbed [42]. This process hinders wax agglomeration and keeps the wax crystals small and dispersed in oil [42]. Such a mechanism might also explain the decline in pour point depressant efficiency above the optimal dosage. It suggests that above the optimal dosage, the excess un-adsorbed additive molecules in the oil may act as links between dispersed wax crystals. This encourages wax agglomeration resulting in increasing pour point [37].

\section{Effect of CNSL-PEG esters on crude oil flow properties}

The effect of additives on flow properties of crude oil was evaluated at a temperature range spanning the oil WAT. Figures 4 and 5 show the effect of shear rate on shear stress and viscosity of blank (undoped) and doped crude oil at three representative temperatures: $50{ }^{\circ} \mathrm{C}$, which is $23.9^{\circ} \mathrm{C}$ above the oil wax appearance temperature (WAT $+23.9^{\circ} \mathrm{C}$ ), $20^{\circ} \mathrm{C}$ (WAT $-6.1{ }^{\circ} \mathrm{C}$ ) and $10^{\circ} \mathrm{C}\left(\right.$ WAT $-16.1^{\circ} \mathrm{C}$ ). At $50{ }^{\circ} \mathrm{C}$ (prior to wax crystallization), the presence of $\mathrm{CN}_{1} \mathrm{PG}(1000 \mathrm{ppm})$ has a slight viscosifying effect on the oil resulting in a marginal increase in shear stress and viscosity (Fig. 4) This is probably due to the fact that at $50{ }^{\circ} \mathrm{C}$, the temperature of the oil is still far above its WAT and there is no crystallized wax which the additive molecules will interact with. However, $\mathrm{CN}_{2} \mathrm{PG}$ (4000 ppm) reduced oil viscosity above WAT. This is partly due to the higher dosage of $\mathrm{CN}_{2} \mathrm{PG}$ compared to $\mathrm{CN}_{1} \mathrm{PG}$. Considering also that $1000 \mathrm{ppm}$ of $\mathrm{CN}_{1} \mathrm{PG}$ depressed the pour point of the crude oil to the same extent as $4000 \mathrm{ppm} \mathrm{CN}_{2} \mathrm{PG}$ (which implies greater efficiency of $\mathrm{CN}_{1} \mathrm{PG}$ ), the observations indicate that differences in the structural features of $\mathrm{CN}_{1} \mathrm{PG}$ and $\mathrm{CN}_{2} \mathrm{PG}$ also play a role in the effect on oil flow properties.

The higher content of alkyl chains and aromatic rings (from CNSL) in $\mathrm{CN}_{2} \mathrm{PG}$ which is the diester derivative, may enhance its solubilization effect on the oil and its interaction with other non-paraffinic oil components, such as asphaltenes and resins, while its higher dosage exerts a greater dilution effect [4] (Fig. 5). Greater oil solubilization and dilution may improve flow even above the WAT. On the other hand, the free polar hydroxyl groups of the glycol present in $\mathrm{CN}_{1} \mathrm{PG}$ (monoester) likely favor the wax-dispersant effect, accounting for its higher pour point depressant efficiency, whereas its solubilization effect is relatively lower due to fewer alkyl chains and aromatic groups.

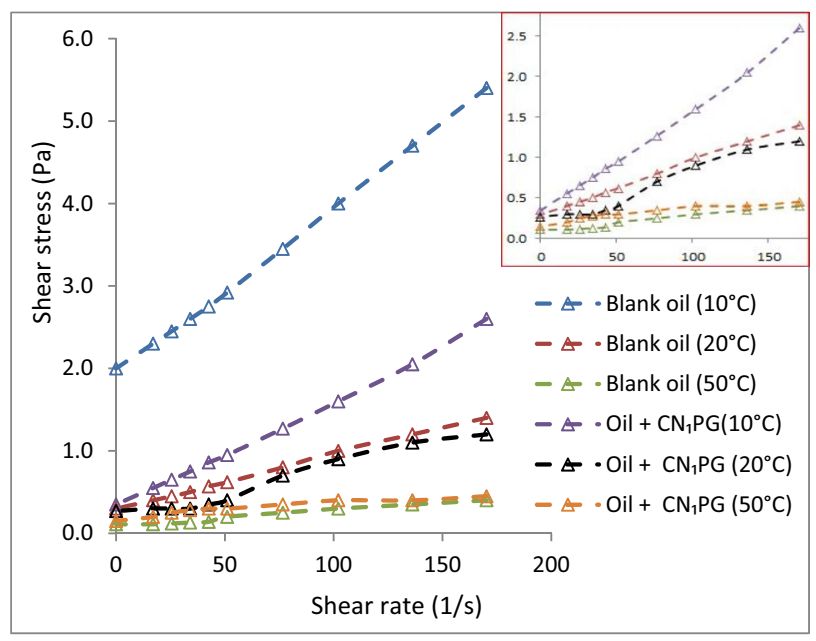

(a)

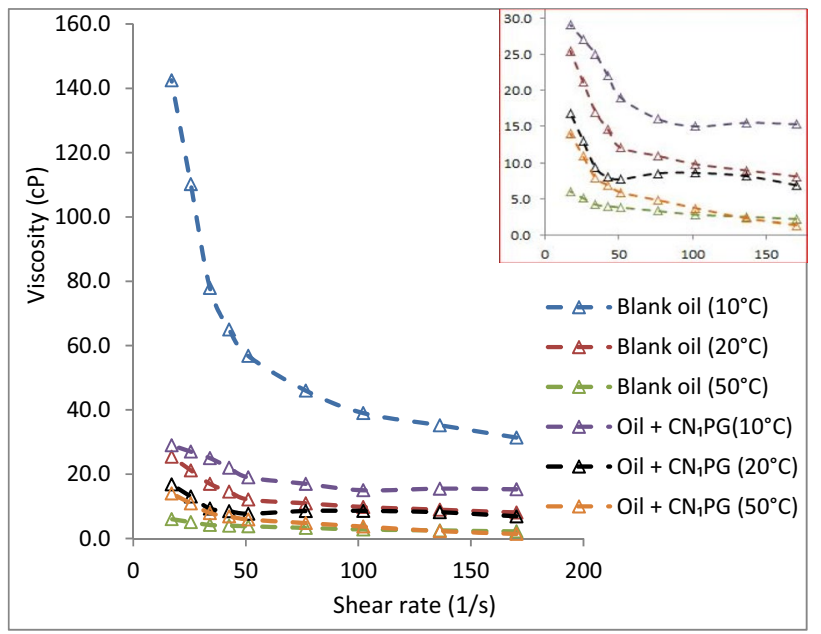

(b)

Fig. 4 Effect of shear rate on shear stress (a) and viscosity (b) of crude oil doped with 1000 ppm $\mathrm{CN}_{1} \mathrm{PG}$

In the temperature region below WAT $\left(20{ }^{\circ} \mathrm{C}\right.$ and $10{ }^{\circ} \mathrm{C}$ ), crystallization of waxes in oil results in increasing shear stress of blank oil with shear rate due to resistance of the oil to shear forces, indicating poor flowability (Fig. 4). It also shows that flowability worsens at lower temperature $\left(10^{\circ} \mathrm{C}\right)$. This is due to increasing wax amount and wax crystal size (Fig. 2) [37]. The presence of the additives results in dramatic reduction in shear stress and viscosity of oil. At $10{ }^{\circ} \mathrm{C}$ for instance, the shear stress of the crude oil, averaged across the experimental shear rates, was reduced by $65.4 \%$ and $76.4 \%$ after addition of $\mathrm{CN}_{1} \mathrm{PG}$ and $\mathrm{CN}_{2} \mathrm{PG}$, respectively. Table 4 summarizes the effect of $\mathrm{CN}_{1} \mathrm{PG}$ and $\mathrm{CN}_{2} \mathrm{PG}$ on the crude oil viscosity as a function of shear rate at $20{ }^{\circ} \mathrm{C}$ and $10{ }^{\circ} \mathrm{C}$. The percentage reduction in dynamic viscosity after doping with

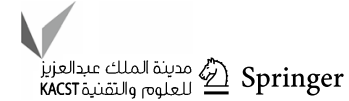




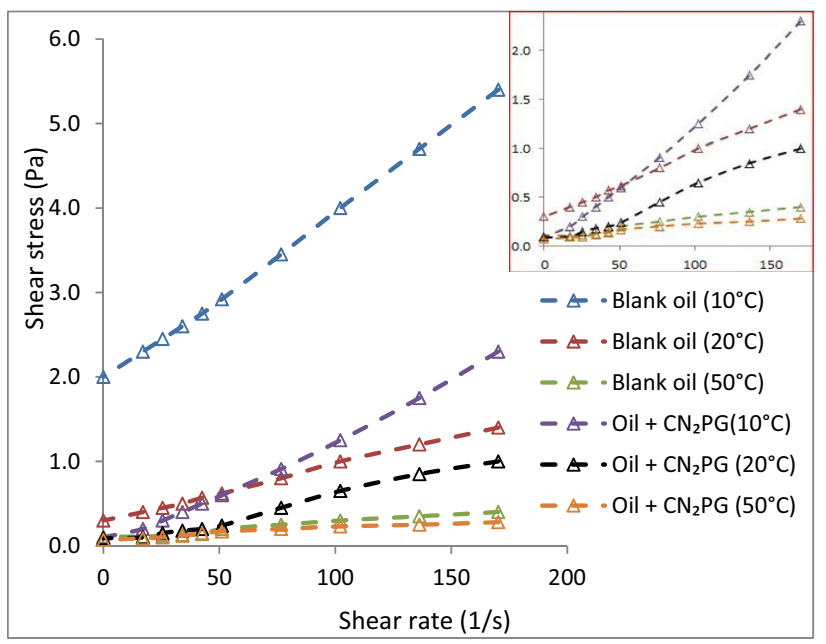

(a)

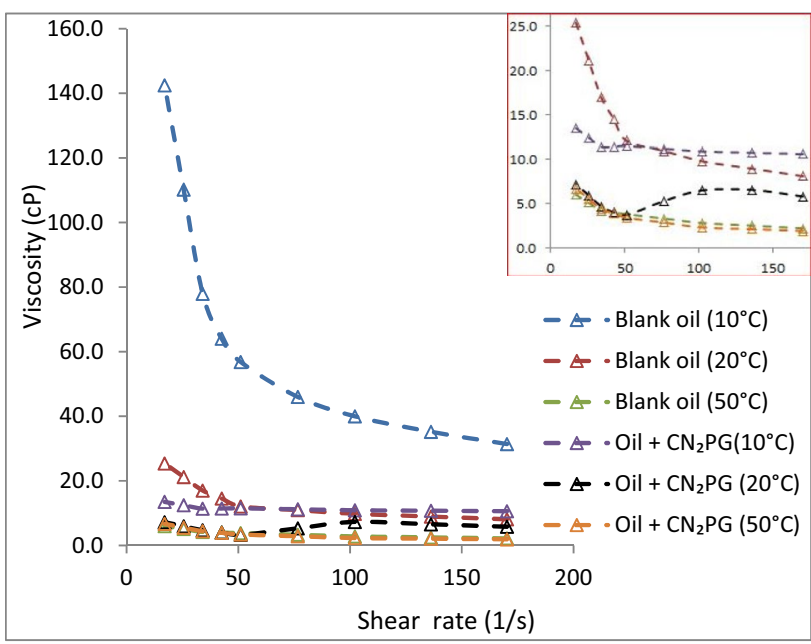

(b)

Fig. 5 Effect of shear rate on shear stress (a) and viscosity (b) of crude oil doped with 4000 ppm $\mathrm{CN}_{2} \mathrm{PG}$

additives increases with decreasing temperature and shear rate which implies that the presence of additives alleviates the normal deterioration in flow properties experienced as waxy crude oils cool.
At $10{ }^{\circ} \mathrm{C}$ and shear rate of $17 \mathrm{~s}^{-1}(10 \mathrm{rpm})$, the dynamic viscosity of crude oil doped with 1000 ppm $\mathrm{CN}_{1} \mathrm{PG}$ and 4000 ppm $\mathrm{CN}_{2} \mathrm{PG}$ was lower than the blank oil by $79.7 \%$ and $90.5 \%$, respectively. Across the experimental shear rate, the average reduction in dynamic viscosity was $65.3 \%$ and $79 \%$ after addition of $\mathrm{CN}_{1} \mathrm{PG}$ and $\mathrm{CN}_{2} \mathrm{PG}$, respectively, indicating lower resistance to shear and decrease in internal frictional forces in the oil (Table 4). This is due to changes previously observed in the wax morphology and micro-structure. The smaller, rounder crystals evolved in doped oil samples have a lower tendency to overlap and network with each other towards formation of agglomerates [45]. Therefore, the wax structures formed in doped oil are likely to be relatively weaker [45]. The greater viscosity reduction effect of $\mathrm{CN}_{2} \mathrm{PG}$ below WAT is also attributable to its greater oil solubilization and dilution effect on the sheared oil compared to $\mathrm{CN}_{1} \mathrm{PG}$.

The viscosity-temperature profile of blank and doped crude oil at constant shear rate $\left(51 \mathrm{~s}^{-1}\right)$ supports previous observations on flow properties of the oil (Fig. 6). The inflection point in the viscosity-temperature plot denotes the onset of wax crystallization which is accompanied by rapid increase in oil viscosity as temperature drops below the WAT. Comparison of the curves for blank oil and doped oils shows that the inflection point for doped oils occurs at a lower temperature which is indicative of improvement in flow. This corroborates the observations in optical microscopy studies. The rapid increase in viscosity of the blank oil is due to the emergence of large over-lapping rod-like wax crystals which form networks in oil, whereas the evolution of small, round crystals in doped oil hinders this process, thus preventing rapid increase in viscosity. Increment in oil viscosity with decreasing temperature in the region below WAT, dropped from $3.3 \mathrm{cP} /{ }^{\circ} \mathrm{C}$ in blank oil to $0.94 \mathrm{cP} /{ }^{\circ} \mathrm{C}$ and $0.57 \mathrm{cP} /{ }^{\circ} \mathrm{C}$ in oil doped with $\mathrm{CN}_{1} \mathrm{PG}$ and $\mathrm{CN}_{2} \mathrm{PG}$, respectively (Fig. 6).

\section{Conclusion}

Low-cost flow improvers for waxy crude oil were prepared by esterification of natural cashew nut shell liquid using polyethylene glycol (PEG-400). The CNSL monoester
Table 4 Percent reduction in viscosity of doped crude oil as a function of shear rate and temperature

\begin{tabular}{lllllllllll}
\hline \multicolumn{10}{c}{ Shear rate $\left(\mathrm{s}^{-1}\right)$} \\
\cline { 2 - 10 } & $10 \mathrm{rpm}$ & $15 \mathrm{rpm}$ & $20 \mathrm{rpm}$ & $25 \mathrm{rpm}$ & $30 \mathrm{rpm}$ & $45 \mathrm{rpm}$ & $60 \mathrm{rpm}$ & $80 \mathrm{rpm}$ & $100 \mathrm{rpm}$ \\
\hline Temp & PPD & $17 \mathrm{~s}^{-1}$ & $25 \mathrm{~s}^{-1}$ & $34 \mathrm{~s}^{-1}$ & $43 \mathrm{~s}^{-1}$ & $51 \mathrm{~s}^{-1}$ & $76 \mathrm{~s}^{-1}$ & $102 \mathrm{~s}^{-1}$ & $136 \mathrm{~s}^{-1}$ & $170 \mathrm{~s}^{-1}$ \\
$10{ }^{\circ} \mathrm{C}$ & $\mathrm{CN}_{1} \mathrm{PG}$ & 79.7 & 75.5 & 67.9 & 66.2 & 66.6 & 63.0 & 61.4 & 56.0 & 51.3 \\
& $\mathrm{CN}_{2} \mathrm{PG}$ & 90.5 & 88.7 & 85.4 & 82.1 & 79.8 & 75.7 & 72.8 & 69.5 & 66.2 \\
$20{ }^{\circ} \mathrm{C}$ & $\mathrm{CN}_{1} \mathrm{PG}$ & 33.9 & 38.4 & 45.3 & 41.6 & 36.4 & 21.9 & 12.3 & 8.90 & 14.8 \\
& $\mathrm{CN}_{2} \mathrm{PG}$ & 71.7 & 71.9 & 72.4 & 72.5 & 72.7 & 51.6 & 25.5 & 26.8 & 28.4 \\
\hline
\end{tabular}




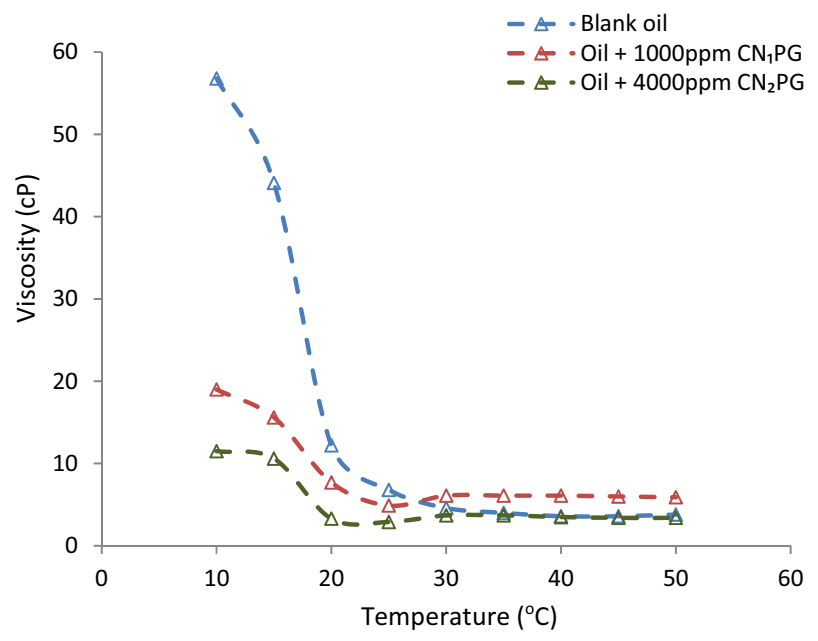

Fig. 6 Effect of temperature on viscosity of blank and doped crude oil at constant shear rate $\left(51 \mathrm{~s}^{-1}\right)$

derivative had higher pour point depressant efficiency, reducing the oil pour point by $12{ }^{\circ} \mathrm{C}$ at $1000 \mathrm{ppm}$. The performance of the CNSL derivatives is influenced by differences in their composition. The additives had a dispersive effect on waxes in crude oil resulting in changes in crystal morphology, such that wax crystals in crude oil doped with additives were smaller and rounder compared to the blank (un-doped) crude oil. Changes in the microscopic properties of the wax crystals resulted in improvement in low-temperature flow properties of the waxy crude oil as shear stress and dynamic viscosity of oil at $10{ }^{\circ} \mathrm{C}\left(16.1{ }^{\circ} \mathrm{C}\right.$ below the wax appearance temperature), was on average reduced by $65 \%$ and $76-79 \%$, respectively. The derivatives can find ready application as inexpensive, eco-friendly additives for production, storage and pipeline transportation of waxy crude oil.

Acknowledgements Technical assistance received from Production Chemistry Laboratory, Shell Petroleum Development Company (SPDC) Port Harcourt, is gratefully acknowledged.

Funding Not Applicable.

Data availability Not available.

Code availability Not applicable.

\section{Declarations}

Conflict of interest On behalf of all the co-authors, the corresponding author states that there is no conflict of interest.

Open Access This article is licensed under a Creative Commons Attribution 4.0 International License, which permits use, sharing, adaptation, distribution and reproduction in any medium or format, as long as you give appropriate credit to the original author(s) and the source, provide a link to the Creative Commons licence, and indicate if changes were made. The images or other third party material in this article are included in the article's Creative Commons licence, unless indicated otherwise in a credit line to the material. If material is not included in the article's Creative Commons licence and your intended use is not permitted by statutory regulation or exceeds the permitted use, you will need to obtain permission directly from the copyright holder. To view a copy of this licence, visit http://creativecommons.org/licenses/by/4.0/.

\section{References}

1. Ajienka JA, Ikoku CU (1990) Waxy crude oil handling in Nigeria: practices, problems, and prospects. Energy Sources 12(14):463-478

2. Ajuong EMA, Breese MC (1998) Fourier transform infrared characterization of Pai wood (Afzelia Africana Smith) extractives. Holz als Roh-und Werkstoff 56:139-142

3. Akinyemi OP, Udonne JD, Efeovbokhan VE, Ayoola AAA (2016) Study on the use of plant seed oils, triethanolamine and xylene as flow improvers of Nigerian waxy crude oil. J Appl Res Technol 14:195-205

4. Al-Sabagh AM, El-Din MRN, Morsi RE, Elsabee MZ (2009) Styrene-maleic anhydride copolymer esters as flow improvers of waxy crude oil. J Pet Sci Eng 65:139-146

5. Al-Sabagh AM, El-Kafrawy AF, Khidr TT, El-Ghazawy RA, Mishrif MR (2007) Synthesis and evaluation of some novel polymeric surfactants based on aromatic amines used as wax dispersants for waxy gas oil. J Dispersion Sci Technol 28:976-983

6. Al-Tameme HJ, Hadi MY, Hameed IH (2015) Phytochemical analysis of Urtica dioica leaves by fourier-transform infrared spectroscopy and gas chromatography-mass spectrometry. J Pharmacognosy Phytother 7(10):238-252

7. Azeem A, Kumar R, Pal B, Naiya TK (2020) Use of novel pour point depressant synthesized from vegetable oil for waxy crude oil. Pet Sci Technol 38(3):185-193

8. Bai C, Zhang J (2013) Effect of carbon number distribution of wax on the yield stress of waxy oil gels. Ind Eng Chem Res 52:2732-2739

9. Bai C, Zhang J (2013) Thermal, macroscopic and microscopic characteristics of wax deposit in field pipelines. Energy Fuels 27:752-759

10. Banerjee S, Kumar R, Mandal A, Naiya TK (2015) Effect of natural and synthetic surfactanton the rheology of light crude oil. Pet Sci Technol 33:1516-1525

11. Bellamy L (1975) The infra-red spectra of complex molecules. Springer, Netherlands

12. Chen G, Tang Y, Zhang J (2011) Synthesis and application of polyaminoamide as new paraffin inhibitor from vegetable oil. Chem Cent J 5:82-84

13. Coates $\mathbf{J}$ (2000) Interpretation of infrared spectra: a practical approach. In: Meyers RA (ed) Encylopedia of Analytical Chemistry, Wiley, Chichester, pp 10815-10837

14. Davidson MR, Nguyen QD, Chang C, Ronningsen HP (2004) A model for restart of a pipeline with compressible gelled waxy crude oil. J Nonnewton Fluid Mech 123(2-3):269-280

15. Deng Q, Bai Y, Gu X, Chen G, Zhang Z (2016) Synthesis of poly-hydrazide from canola oil and use as a flow improver for crude oil. Adv Eng Res 103:281-285

16. Eke WI, Kyei SK, Ajienka J, Akaranta O (2021) Effect of biobased flow improver on themicroscopic and low-temperature flow properties of waxy crude oil. J Petrol Explor Prod Technol 11:711-724

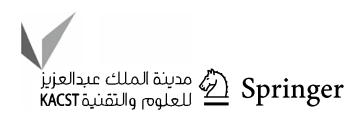


17. Eke WI, Achugasim O, Ajienka J, Akaranta O (2021) Glycerolmodified cashew nut shell liquid as eco-friendly flow improvers for waxy crude oil. Pet Sci Technol 39(4):101-114

18. Eke, WI, Achugasim O, Ofordile SE, Ajienka J, Akaranta, O (2019) Performance Evaluation of Cashew Nut Shell Liquid CNSL as Flow Improver for Waxy Crude Oils. SPE -198721 MS. In: Nigeria Annual International Conference and Exhibition, Lagos.

19. Finar IL (1975) Organic chemistry Volume 2: Spectrochemistry and the Chemistry of Natural Products, 5th edn, Pearson Education, India

20. Gandhi T, Patel M, Dholakiya BK (2012) Studies on effect of various solvents on extraction of cashew nut shell liquid (CNSL) and isolation of major phenolic constituents from extracted CNSL. J Nat Prod Plant Resour 2(1):135-142

21. Gedam PH, Sampthkumaran PS (1986) Cashew nut shell liquid: extraction. Chem Appl Progr Org Coatings 14:115-157

22. Gnanasambandam R, Proctor A (2000) Determination of pectin degree of esterification by diffuse reflectance Fourier transform infrared spectroscopy. Food Chem 68:327-332

23. Hao LZ, Al-Salim HS, Ridzuan NA (2019) Review of the mechanism and role of wax inhibitors in the wax deposition and precipitation. Pertnaika J Sci Technol 27(1):494-526

24. Huyen QTM, Chau NGM, Tuan NBH, Thoa DTK, Khanh NV (2012) Synthesis routes for potential pour point depressants from cashew nut shell liquids. J Cataly Adsorp 1:176-183

25. Huyen QTM, Khanh NV (2014) Synthesis of crude oil pour point depressants via Polycondensation of cashew nut shell liquid. Petrovietnam 6:48-52

26. Jia B, Zhang J (2012) Yield behavior of waxy crude gel: effect of isothermal structure development before prior applied stress. Ind Eng Chem Res 15:10977-10982

27. Jinjun Z, Bo Y, Hongying L, Qiyu H (2013) Advances in rheology and flow assurance studies of waxy crude. Pet Sci 10:538-547

28. Khidr TT, Doheim MM, El-Shamy OAA (2015) Pour point depressant of fuel oil using non-ionic surfactants. Pet Sci Technol 33:1619-1626

29. Khidr TT, Doheim MM, El-Shamy OAA (2015) Effect of ethoxylate on pour point depressant of fuel oil. Energy Sources 37:1697-1703

30. Li N, Mao G, Shi X, Tian S, Liu Y (2018) Advances in the research of polymeric pour point depressants for waxy crude oils. J Dispersion Sci Technol 39(8):1165-1171

31. Mansourpoor M, Azin R, Osfouri S, Izadpanah AA (2019) Experimental investigation of waxdeposition from waxy oil mixtures. Appl Petrochem Res 9:77-90

32. Misra S, Baruah S, Singh K (1995) Paraffin problems in crude oil production and transportation: a review. SPEPF 10(1):50-54
33. Narula K (2019) Global energy system and sustainable energy security. In: The maritime dimension of sustainable energy security. Lecture Notes in Energy, Springer, Singapore, pp 68. https:// doi.org/https://doi.org/10.1007/978-981-13-1589-3_2

34. Oliveira LMSL, Nunes RCP, Melo IC, Ribeiro YLL, Reis LG, Dias JCM, Guimaraes RCL, Lucas EF (2016) Evaluation of the correlation between wax type and structure/behavior of pour point depressant. Fuel Process Technol 149:268-274

35. Olsen DK, Ramzel B (1992) Heavy oil refining and transportation: effect on the feasibility of increasing domestic heavy oil production. Fuel 71:1391-1401

36. Ragunathan T, Husin H, Wood CD (2020) Effect of crude palm oil and crude palm kernel oil upon wax inhibition. ACS Omega 5(31):19342-19349

37. Sharma S, Mahto V, Sharma VP (2014) Effect of flow improvers on rheological and micrscopic properties of indian waxy crude oil. Ind Eng Chem Res 53:4525-4533

38. Soedarmo AA, Daraboina N, Lee HS, Sarica C (2016) Microscopic study of wax precipitation- static conditions. Energy Fuels 30(2):954-961

39. Tyman JH (1976) Determination of the components phenols in natural and technical cashew nut-shell liquid by gas-liquid chromatography. Anal Chem 48(1):30-34

40. Tyman JHP, Johnson RA, Muir M, Rokhgar R (1989) Extraction of natural cashew nut-shell liquid from the cashew nut (Anacardium occidentale). J Am Oil Chem Soc 66(4):553-557

41. Venkatesan R, Nagarajan NR, Paso K, Yi YB, Sastry AM, Fogler HS (2005) The strength of paraffin gels formed under static and flow conditions. Chem Eng Sci 60:3587-3598

42. Yao B, Chen W, Li C, Yang F, Sun G, Wang G, Xu H (2020) Polar asphaltenes facilitate the flow improving performance of polyethylene-vinyl acetate. Fuel Process Technol 207:106481

43. Yao B, Mu Z, Li C, Yang F, Zhang X (2017) Effective flow improving agents for waxy crude oil. Pet Sci Technol 35(7):1775-1783

44. Yi S, Zhang J (2011) Relationship between waxy crude oil composition and change in the morphology and structure of wax crystals induced by pour-point depressant beneficiation. Energy Fuels 25:1686-1696

45. Zhao Y, Kumar L, Paso K, Safieva J, Sariman MZB, Sjoblom J (2012) Gelation behavior of model wax-oil and crude oil systems and yield stress model development. Energy Fuels 26:6323-6331

Publisher's Note Springer Nature remains neutral with regard to jurisdictional claims in published maps and institutional affiliations. 